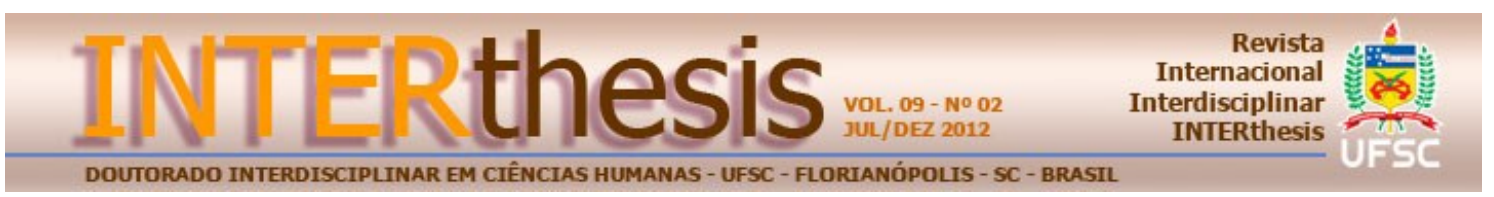

\title{
CLASSIFICAR E MEDICAR: A GESTÃO BIOPOLÍTICA DOS SOFRIMENTOS PSÍQUICOS
}

\section{CLASSIFYING AND MEDICATING: THE BIO-POLITICAL MANAGEMENT OF PSYCHIC SUFFERINGS}

\section{CLASIFICAR Y MEDICAR: LA GESTIÓN BIOPOLITICA DE LOS SUFRIMIENTOS PSÍQUICOS}

Sandra Caponi ${ }^{1}$

\section{Resumo:}

Considerando que a palavra biopolítica se transformou em um marco de referência para inúmeros debates e temas, muitas vezes sem os devidos questionamentos sobre seus alcances e limites, pretendo analisar neste escrito, inicialmente, os eixos centrais em relação aos quais se articula o conceito foucaultiano de biopolítica: 1) a centralidade da norma e a oposição normalidade-patologia; (2) os estudos estatísticos referidos aos fenômenos vitais que caracterizam as populações; (3) o problema do risco e os dispositivos de segurança; (4) o governo das populações como forma de gestão que exclui o governo de si. Posteriormente, será discutido um texto recentemente publicado pelo ex-chefe do grupo de tarefas do Manual de Diagnóstico e Estatística de Transtornos Mentais (DSM), onde ele questiona o atual processo de elaboração da quinta edição desse Manual. Essas críticas permitem mostrar que o Manual se articula entorno dos mesmos eixos que caracterizam a biopolítica das populações, configurando uma estratégia, hoje hegemônica, de gestão dos sofrimentos psíquicos.

Palavras chave: Biopolítica. DSM. Diagnósticos. Foucault.

\section{Abstract:}

Considering that the word 'bio-politics' has become the referential framework of multiple debates and topics, often without the due reflections concerning its scope and limits, in this paper, I intend to analyze, firstly, the central axes on which Foucault's concept of bio-politics articulates: 1) the centrality of the norm and the opposition normality-pathology; (2) the statistical studies referred to the vital phenomena that characterize populations; (3) the problem of the risk and the mechanisms of security; (4) the government of the populations as a form of management that excludes the individual self-government. After that, a recent paper published by the former head of the task group of the Diagnostic and Statistical

\footnotetext{
1 Doutora em Filosofia pela Universidade Estadual de Campinas (UNICAMP). Professora do Departamento de Sociologia e Ciências Políticas e do Programa Interdisciplinar em Ciências Humanas, Florianópolis, SC, Brasil. Pesquisadora de CNPq. E-mail: sandracaponi@gmail.com
} 
Manual of Mental Disorders (DSM) will be discussed. In that paper, he questions the current process of preparing the fifth edition of the Manual. This criticism allows us to show that this Manual is articulated around the same axes which characterize the bio-politics of populations, outlining a strategy, today hegemonic, for managing the psychic sufferings.

Keywords: bio-politics, DSM, diagnoses, Foucault.

\section{Resumen:}

Considerando que la palabra biopolítica se transformó en un marco de referencia para innúmeros debates y temas, muchas veces sin los debidos cuestionamientos sobre sus alcances y límites, pretendo analizar en este escrito, inicialmente, los ejes centrales en relación a los cuales se articula el concepto foucaultiano de biopolítica: 1) la centralidad de la norma y la oposición normalidad- patología; (2) los estudios estadísticos referidos a los fenómenos vitales que caracterizan a las poblaciones; (3) el problema del riesgo y los dispositivos de seguridad; (4) el gobierno de las poblaciones como forma de gestión que excluye el gobierno de sí. Posteriormente, será discutido un texto recientemente publicado por el ex jefe del grupo de tareas del Manual de Diagnóstico y Estadística de Trastornos mentales (DSM), donde cuestiona el actual proceso de elaboración de la quinta edición de ese Manual. Esas críticas permiten mostrar que ese Manual se articula en torno a los mismos ejes que caracterizan a la biopolítica de las poblaciones, configurando una estrategia, hoy hegemónica, de gestión de los sufrimientos psíquicos.

Palabras-clave: biopolítica, DSM, diagnósticos, Foucault.

No curso Em defesa da Sociedade (1997), Foucault explora as alianças entre a constituição dos estados modernos e a biopolítica, destacando o lugar estratégico ocupado pelas empresas colonialistas e pelas tecnologias de governo destinadas aos povos colonizados. Dirá que, para que a biopolítica possa exercer uma relação positiva com a vida, para que ela possa construir técnicas de governo destinadas a maximizar e aumentar a força e o equilíbrio das populações, as sociedades modernas têm aceitado conviver, de modo explicito ou implícito, com sua negação: os processos de exclusão de tudo aquilo que possa aparecer como uma ameaça, ou como uma fonte de degradação da vida.

Falará de estratégias que se validam num processo de regularização por exclusão. E argumentará que a aceitação dessas estratégias ocorreu como resultado de uma partição operada no campo do biológico pelo racismo. O racismo deve entender-se num sentido amplo e não literal, não se limita a distinção de raças, mas se refere a uma verdadeira hierarquização biológica pela qual se instalam vínculos de exclusão, de negação e até de aversão, entre grupos humanos.

O racismo aparecia como o elemento central para compreender as estratégias de exclusão e morte edificadas nos séculos XVIII e XIX pelos nascentes 
Estados modernos. Nesse momento os discursos racistas pareciam estar validados e legitimados por uma proliferação de novos saberes considerados científicos, particularmente aqueles saberes provenientes do campo da medicina, da biologia e da criminologia que, na última metade do século XIX, se transformaram em referência inquestionável para as intervenções dos alienistas e higienistas.

Certamente em nossa modernidade tardia as estratégias biopolíticas referidas às populações já não podem inscrever- e nesse mesmo marco de análise. Já não seria legitimo falar de discursos científicos ou de estratégias de poder construídas entorno ao eixo do racismo, ainda que em muitos casos os discursos racistas perdurem e se multipliquem fora do campo dos saberes aceitos pela comunidade acadêmica. Ainda que possamos falar de uma completa superação dos limites impostos pelo racismo, limites que observamos cotidianamente com os problemas derivados dos fluxos migratórios, da xenofobia e da intolerância racial em diferentes países do mundo, hoje se faz necessário pensar de que modo operam as estratégias biopolíticas em contextos mais amplos que excedem e integram $o$ clássico problema do racismo.

Novos discursos e novos saberes construídos entorno ao eixo do normalpatológico, que já não podem ser pensados sob o eixo do racismo, impõem o desafio de pensar as estratégias biopolíticas hoje existentes. Novos discursos e certezas se instalam no campo das ciências da vida, novas intervenções sobre as populações que se validam nas promessas de um saber médico e psiquiátrico obsecado por antecipar os riscos (CASTIEL, 2007), evitar a dor e garantir a meta impossível de uma vida sem sofrimentos. Analisar o surgimento dessas novas formas de maximização da vida que adota a biopolítica na contemporaneidade, assim como deter-se nos novos modos de exclusão que ela implica, exige um entendimento prévio sobre os alcances e limites do conceito de biopolítica.

Tendo esta problemática como marco geral, tentarei responder a uma questão específica: seria possível pensar a atual expansão de diagnósticos psiquiátricos referidos a comportamentos cotidianos, como sendo uma estratégia biopolítica hoje hegemônica e quase universalmente aceita?

Considerando que a palavra biopolítica tornou-se um marco de referência para inúmeros debates e temas, muitas vezes sem os devidos questionamentos sobre seus alcances e limites, pretendo: (I) inicialmente, analisar os eixos centrais em relação aos quais se articula o conceito foucaultiano de biopolítica; para (II), 
posteriormente, centrar a discussão num texto recentemente publicado por Allen Frances $(2010)^{2}$ (ex chefe do grupo de tarefas do DSM) onde questiona o processo de elaboração em curso da quinta edição do Manual de Diagnóstico e Estatística de Transtornos Mentais, o DSM V. A quarta edição desse Manual (DSM IV) é amplamente utilizada como referência obrigatória para definir diagnósticos psiquiátricos no mundo inteiro, por profissionais de saúde, psiquiatras e até educadores.

É possível argumentar que, muitas das críticas formuladas por Frances em relação ao DSM V, ainda que perfeitamente aplicáveis ao DSM IV (por ele coordenado), permitem evidenciar que o Manual de Diagnóstico e Estatística de Transtornos Mentais, se articula entorno dos mesmos eixos que, de acordo com Foucault, possibilitaram a criação dos dispositivos de segurança próprios da biopolítica das populações. Como veremos a dificuldade em estabelecer fronteiras mais ou menos precisas entre o normal e o patológico (a diferencia do que ocorre no campo da medicina clínica, onde a psiquiatria encontra legitimidade); a preocupação pela antecipação dos perigos e pelo controle de riscos; o uso das estáticas com a finalidade de demarcar fronteira entre normalidade e desvios que devem ser corrigidos e antecipados, são elementos que permitem entender a estratégia de classificação e diagnóstico do DSM como um dispositivo biopolítico.

\section{O CONCEITO DE BIOPOLÍTICA}

O conceito de biopolítica foi enunciado pela primeira vez por Michel Foucault em 1976 no último capítulo de $A$ Vontade de Saber (1978), porém, Foucault desenvolve e leva até o limite as implicações teórico-politicas desse conceito em dois cursos do College de France, Em defesa da sociedade (FOUCAULT, 1997) e Segurança, território e população (FOUCAULT, 2004). Será fundamentalmente nesses dois textos e no curso Os Anormais (1999) onde Foucault define o conceito de biopolítica. Mais tarde, no Nascimento da biopolítica (FOUCAULT, 2005), dirá que se propõe realizar um estudo sobre a arte de governar no liberalismo e

\footnotetext{
${ }^{2} \mathrm{O}$ texto de Allen Frances que aqui será analisado tem suscitado diversos debates na comunidade mundial de psiquiatras, psicanalistas e trabalhadores do campo da saúde mental (MALDONADO et ali, 2011). A relevância desse texto radica em que, pela primeira vez, um psiquiatra que estava diretamente comprometido com a classificação do DSM, aponta as falhas e dificuldades inerentes a essa estratégia, reforçando os argumentos apresentados pelos coletivos "Stop DSM" organizados em Espanha e França em 2010.
} 
neoliberalismo com a finalidade de entender as condições de possibilidade da biopolítica. No entanto esse conceito será abandonado ao longo do texto.

$\mathrm{Na}$ aula do dia 17 de março do curso ministrado no College de France em 1976, Em defesa da sociedade (1997), Foucault aprofunda e desenvolve o conceito de biopolítica, estabelecendo os alcances e limites de um conceito que permanece absolutamente atual e que tem possibilitado inúmeras reflexões, desdobramentos e aplicações aos mais diversos campos de estudo. Como é sabido, a publicação dos cursos do College de France ministrados por Foucault desde 1971 até sua morte em 1984, ainda inacabada, contribuiu a despertar um renovado interesse por seu trabalho, e muito particularmente pelo conceito de biopolítica.

Como já tinha sido afirmado em $A$ Vontade de Saber, no curso Em defesa da sociedade, Foucault dirá que a fins do século XVIII e inícios do século XIX se produz uma transformação no modo de organizar e gerir o poder, uma mutação pela qual a antiga potestade do soberano, seu direito sobre a vida e a morte dos súbditos, considerada como um de seus atributos fundamentais pela teoria jurídica clássica, deixará lugar a um novo modo de organizar as relações de poder. O velho direito de deixar viver e de fazer morrer próprio do soberano, será substituído pelo direito ou pelo poder de fazer viver e deixar morrer, configurando-se assim o domínio dos biopoderes referidos aos corpos e às populações. Tudo ocorre como se o poder de soberania descobrisse sua inoperância para lidar com os fenômenos próprios da nascente sociedade industrial: a explosão demográfica, os problemas de urbanização, os novos conflitos derivados da industrialização. Esse poder de soberania sofrerá um primeiro processo de acomodação com as tecnologias disciplinares estudadas por Foucault em Vigiar e Punir (1979): estratégias que se dirigem aos corpos, e que estão destinadas a multiplicar sua força e sua capacidade de trabalho e a diminuir sua força política.

Um segundo processo de acomodação surgirá mais tarde, fortalecendo-se ao longo do século XIX sem excluir ou substituir a tecnologia disciplinar, mas integrando-a e utilizando-a parcialmente para dirigir-se a um novo objeto de intervenção: os processos biológicos e biossociológicos próprios dos fenômenos populacionais. Enquanto as disciplinas se referem ao corpo, o novo poder regulador não se dirige ao corpo, mas à vida, sendo seu objeto especifico de interesse o homem enquanto ser vivo, o homem enquanto espécie biológica. A diferença das disciplinas: 
A nova tecnologia que será posta em prática se refere à multiplicidade de homens, não enquanto corpos individuais, mas na medida em que eles constituem uma massa global afetada por esses processos de conjunto que são próprios da vida, como os processos de nascimento, morte, reprodução, doenças, etc. (FOUCAULT, 1997, p. 216).

Trata-se, pois, de duas estratégias de poder que se sucedem: a primeira individualizante, a segunda massificadora, a primeira referida ao homem enquanto possuidor de um corpo, a segunda referida ao homem enquanto faz parte de uma espécie biológica, a espécie homem.

Essa nova tecnologia de poder demanda a construção de novos saberes sobre as populações, os registros e estatísticas referidas à proporção de nascimentos e mortes, às taxas de reprodução, de fecundidade, de longevidade. Um imenso conjunto de dados demográficos começará a ser coletado, inicialmente em nível local, para logo possibilitar comparações e estatísticas globais que serão centralizadas por organismos estatais como os registros nacionais de estatística e demografia. Esses indicadores quantitativos, na medida em que são pensados como um fiel reflexo da realidade econômica de um país, do poder de um Estado, ou do progresso dos povos, constituem a base privilegiada a partir da qual serão construídas estratégias concretas de intervenção sobre as populações.

A biopolítica das populações tem alguns espaços privilegiados de intervenção, dentre eles: as políticas de controle de natalidade; o controle das morbidades e endemias (que substituirá o temor pelas grandes epidemias vistas como ameaça desde a Idade Media); o estudo e o controle da extensão e duração das patologias prevalentes, pensadas como fatores que debilitam a força de trabalho e implicam custos econômicos para todos; as intervenções sobre a velhice, os acidentes, as doenças e anomalias que excluem os indivíduos do mercado de trabalho; a gestão das relações entre espécie humana e o meio externo, seja que se trate de problemas com o clima e a natureza (os pântanos, por exemplo), ou com o meio urbano. Nessas estratégias de intervenção se articulam diversos domínios do saber e da ação política. Por um lado, os conhecimentos elaborados pela higiene, a medicina social, a demografia e a estatística, por outro as estratégias de poder que adotam a forma de esquemas de regulação, gestão, assistência, controle de riscos e mecanismos de segurança. 
A biopolítica se constitui como uma tecnologia científica - política que se exerce sobre as populações entendidas como uma multiplicidade biológica, que se refere especificamente aos processos vitais, e que tem como preocupação imediata antecipar os riscos. Assim, esse conjunto de fenômenos que se apresentam como aleatórios e imprevisíveis, quando se analisam como fatos que afetam a um determinado indivíduo, aparecem como constantes que é possível antecipar, quando são observados em perspectiva populacional. Os estudos estatísticos permitirão estudar esses fenômenos em séries de curta ou longa duração e desse modo antecipar os riscos ou perigos ao qual essa população estaria submetida. Essas predições e estimações estatísticas referidas a fatos sociais (populacionais) e não a indivíduos, permitem criar mecanismos reguladores destinados a manter um estado de equilíbrio ou atingir a média estatística desejada (baixar a mortalidade, alongar a vida, estimular a natalidade) (FOUCAULT, 2004).

O objetivo último da biopolítica será instalar para cada risco ou perigo que possa vir a ocorrer, mecanismos de segurança que têm certas semelhanças e certas diferenças com os mecanismos disciplinares. Ambos propõem-se a aumentar e maximizar a força de trabalho, temos assim: "Uma tecnologia de poder sobre a população enquanto tal, sobre o homem como ser vivo, um poder contínuo, científico, que é o poder de fazer viver" (FOUCAULT, 1997, p. 220).

Do mesmo modo que nas disciplinas se conjuga a maximização das forças produtivas com a diminuição da capacidade política, na biopolítica deve ser considerada outra duplicidade que se refere, por um lado, à maximização da força e da vitalidade das populações e, por outro, ao esquecimento daqueles indivíduos que se mantêm às margens do auxílio e da proteção estatal, aqueles que os governos simplesmente ignoram ou "deixam morrer".

Para poder compreender os alcances e limites deste conceito complexo e ambíguo que é a biopolítica, resulta indispensável analisar os dois elementos que a compõem. Isto é, tentar explicitar de que modo operam e se vinculam entre si os eixos do vital, "o bios", e do político, no campo do debate aberto por Foucault. Particularmente, deveremos analisar duas questões: (a) de que modo o vital se estabelece como eixo articulador de uma multiplicidade de discursos e saberes referidos ao normal e o patológico; e (b) quais são as dificuldades e limites inerentes ao conceito de "política" quando este se refere ao domínio do vital. 


\section{a. O bios como objeto de saber}

Ainda que nos Cursos do College de France, Foucault explore as diversas faces que adota a biopolítica na modernidade, não existe uma referência clara à noção de vida sobre a qual se constrói e se articula esse conceito. Alguns autores, como Didier Fassin, opinam que essa noção, que constitui o coração da biopolítica, não foi suficientemente explicitada por Foucault (FASSIN, 2006). É verdade que nos cursos não existe nenhum momento dedicado a analisar exclusivamente essa noção, porém, para poder compreender a especificidade deste bios, que antecede à política, resulta necessário situá-lo numa perspectiva mais ampla, lembrando que Foucault dedicou diversos textos e estudos a problematizar essa noção.

De fato a problemática da vida acompanha Foucault desde seus primeiros escritos, particularmente desde O Nascimento da Clínica (1987) de 1963 e As Palavras e As Coisas (1983), até o último texto que envia para publicação pouco antes de sua morte, uma texto em homenagem a Georges Canguilhem denominado A vida, A Experiência e A Sociedade (apud FASSIN, 2006). Trata-se de um problema que ele nunca abandonou, de modo que, para compreender o conceito de vida ao qual a biopolítica se refere, deveremos abordá-lo respeitando sua complexidade.

Inicialmente, será necessário fazer referência às reflexões dedicadas aos discursos científicos referidos à vida, provenientes do campo da biologia e da medicina, que foram centrais nos estudos arqueológicos; logo abordar os diversos modos através dos quais opera a partição entre o normal e o patológico na construção de tecnologias e estratégias de poder; para, por fim, analisar o modo como se vinculam os processos de subjetivação e a construção de subjetividades com nossa corporeidade, nossos sofrimentos físicos, nossa decadência vital e, em fim, nossa própria morte.

A centralidade da noção de vida nos estudos biopolíticos torna-se evidente na seguinte afirmação de Foucault:

Parece-me que um dos fenômenos fundamentais do século XIX tem sido o que poderíamos denominar uma invasão da vida pelo poder: ou se vocês desejam, um exercício de poder sobre o homem enquanto ser vivo, uma sorte de estatização do biológico, ou pelo menos uma certa tendência ao que se poderia denominar uma estatização do biológico (FOUCAULT, 1997, p. 286). 
Esse texto não só permite situar a noção vida como articuladora de novos domínios de saber e de intervenção, ele delimita claramente o alcance dessa noção. O poder não se refere aqui à vida cotidiana, nem ao nosso dia a dia, nem à vida como fato existencial, trata-se de uma clara identificação da vida com o domínio do biológico, trata-se da vida enquanto objeto de estudo da biologia, da medicina, em fim desses saberes denominados, justamente, ciências da vida.

Como já foi dito, Foucault considera que um fato determinante na construção das sociedades modernas é o processo pelo qual a vida, isto é, a vida que compartilhamos com os animais, passa a ser investida por cálculos explícitos e por estratégias de poder: o momento em que o biológico ingressa como elemento privilegiado no registro da política. Assim, no Nascimento da Biopolítica afirma que seu objetivo é:

entender de que modo a prática governamental tentou racionalizar os fenômenos colocados por um conjunto de seres vivos constituídos como uma população: problemas relativos à saúde, à higiene, à natalidade, à longevidade, às raças e outros (Foucault, 2004, p. 27).

Para poder tematizar esse "bios", entorno ao qual se estruturam as estratégias biopolíticas, será necessário fazer referência a um registro que é ao mesmo tempo científico e político, pois a vida se apresenta ao mesmo tempo como fato biológico e como objeto de intervenção e de poder. Será necessário olhar para a construção de discursos e classificações científicas e, ao mesmo tempo, para as práticas concretas de intervenção que transformam a vida dos indivíduos.

Será necessário lembrar as dívidas que Foucault mantém, desde o Nascimento da Clínica até sua última publicação, com Georges Canguilhem. Os estudos que Canguilhem (1990a) dedica à medicina e à biologia, em particular sua crítica frontal ao modo como se estabelecem os parâmetros de normalidade e patologia nas ciências da vida pelo recurso a padrões estatísticos, não podem ser desconsiderados quando analisamos os alcances e limites da noção de vida embutida no conceito de biopolítica.

Canguilhem soube mostrar, com extrema clareza, a duplicidade constitutiva do conceito de normal, essencial para compreender os fatos biológicos e as intervenções médicas. Por um lado, o normal define os valores de referência, as 
médias e as variações admissíveis para um determinado fenômeno biológico (seja a taxa de colesterol ou de suicídio), estabelecidas a partir dos valores estatisticamente mais frequentes. Por outro lado, trata-se de um conceito valorativo e normativo que define aquilo que deve ser considerado desejável em determinado momento e em determinada sociedade. Assim, é pelo recurso das normas e médias estatísticas que a medicina pode chegar a afirmar de que modo um fato biológico, uma função orgânica, um processo vital ou uma conduta direta ou indiretamente vinculada ao biológico deve ou deveria ser.

O saber médico e a noção de norma, entorno da qual esse saber se constrói, são indispensáveis para compreender as estratégias biopolíticas: não somente porque permitem a articulação entre o conhecimento científico e as intervenções concretas, mas também porque é entorno da norma que podem ser criadas estratégias de poder que correspondem aos corpos dos indivíduos (as disciplinas) e aos processos biológicos da espécie (a biopolítica). Como afirma Foucault

o elemento que circula do disciplinário ao regulador, que se aplica do mesmo modo aos corpos e às populações, que permite controlar a ordem disciplinar dos corpos e os eventos aleatórios de uma multiplicidade biológica, esse elemento que circula de um a outro, é a norma (FOUCAULT, 1997, p. 225).

Na terceira conferência publicada no livro Segurança, Território e População (FOUCAULT, 2004), Foucault estabelece uma distinção entre as estratégias de normação, próprias da sociedade disciplinar, e as estratégias de normalização, próprias da biopolítica das populações. O certo é que falar de um poder que se refere à vida significa afirmar que o homem enquanto espécie se transformou em objeto de tecnologias do saber e poder normalizadoras que permitem regularizar os fatos biológicos próprios das populações, tendo como marco de referência os parâmetros estabelecidos pelas ciências da vida.

\section{b. A biopolítica como governo sobre a vida}

Mas se a vida remete, por um lado, por via das normas ao campo dos discursos biológicos, médicos e higiênicos, por outro lado, ela também se vincula de um modo peculiar ao campo do político. De fato, deveríamos dizer que quando Foucault fala de biopolítica não é realmente a política da vida o que está em 
questão, mas as práticas sociais que se exercem sobre os corpos e as populações. A noção de vida voltará ao centro da cena, não já como objeto de tematização das ciências biológicas, mas sim como um espaço privilegiado para garantir a governabilidade e a gestão das populações nas sociedades modernas.

O exercício da biopolítica supõe que, para poder governar as sociedades, basta reduzir a multiplicidade de circunstâncias próprias da condição humana a sua dimensão biológica, ao domínio do vital, esse domínio que limita aos homens a sua identidade enquanto espécie. No entanto, e aqui se encontra a maior contradição inerente ao conceito de biopolítica, na medida em que o governo das populações opera exclusivamente sobre fatos biológicos, ele deverá deixar nas sombras, como já o antecipara Aristóteles, justamente a dimensão política da existência, nossa capacidade de reflexão e diálogo argumentativo, nossos vínculos sociais, nossos afetos, sonhos e pesadelos.

Lembremos que, não por acaso, é justamente por oposição à concepção aristotélica de "homem" que Foucault pensa o exercício da biopolítica. Nesta frase, inúmeras vezes citada, afirma:

Por milênios o homem permaneceu o que era para Aristóteles: um animal vivente e, além disso, capaz de existência política; o homem moderno é um animal em cuja política está em questão sua existência como ser vivo (FOUCAULT, 1978, p.184).

Com a finalidade de entender a complexa articulação entre vida e política suposta em essa afirmação, será necessário, como afirma Didier Fassin (2006), fazer referência a dois filósofos que de modo direto ou indireto estão presentes nos argumentos de Foucault: um é Georges Canguilhem (1990a) e o outro é Hannah Arendt (1993). Vimos de que modo a noção de vida entorno da qual se constrói o conceito de biopolítica é fortemente devedora dos estudos epistemológicos que Canguilhem dedica às ciências da vida: a centralidade da norma, as referências a médias e desvios estatísticos, uma vida enfim sujeita a cálculos, a medidas de frequência a antecipação de riscos, onde não fica nenhum espaço, como afirma Canguilhem, para o corpo vivido, para o corpo subjetivo, único parâmetro capaz de determinar o momento preciso em que se inicia uma doença (Canguilhem, 1990b). A partir da análise de Canguilhem a vida parece ser vista pelas ciências biológicas e médicas sempre mediada pela ideia de norma. 
Se Canguilhem influencia o modo como Foucault pensa a vida a partir de uma perspectiva epistemológica, é recorrendo a Hannah Arendt (1993) que podemos compreender a relação entre vida e política entorno da qual se tece o conceito de biopolítica. Para Fassin, não é possível imaginar que Foucault ignore a Hannah Arendt, pois ainda que nunca tenha sido citada, ela "também colocou a vida no centro de sua obra, após a tipologia das três formas de vida da Condição Humana na Modernidade, até sua análise do processo vital realizado em Sobre a Revolução" (FASSIN, 2006, p. 38). Diversos autores mencionaram a proximidade existente entre Arendt e Foucault em relação ao modo como pensam os fenômenos vitais (AGEMBEN, 2002; CAPONI, 2000; ORTEGA, 2004). E de fato é muito simples compreender essa proximidade na medida em que tanto Arendt como Foucault mencionam suas dívidas com Aristóteles e seu modo de pensar o domínio do biológico por oposição ao espaço do político.

É por referência a Aristóteles que se entende a grande novidade que se produz no mundo moderno, da qual falam tanto Foucault quanto Arendt: a identificação entre o vital e o político. No mundo grego, os fatos vinculados com o biológico faziam parte do domínio pré-político e estavam reservados ao âmbito do privado, isto é, ao oikos, a vida doméstica organizada entorno das necessidades da família. Um espaço que se opõe ao registro do público, entendido como domínio da vida politicamente qualificada.

Se aceitamos a distinção entre vida e política estabelecida por Aristóteles e retomada por Arendt, quiçá devamos afirmar que o conceito de biopolítica, que literalmente significa "política da ou sobre a vida", implica um oxímoro, implica uma contradição interna entre dois domínios irredutíveis. Mais que uma política da vida, a biopolítica refere-se a um modo de gerir e administrar as populações. A vida que aqui está em jogo não é a de cidadãos capazes de diálogo e existência jurídicopolítica, mas a de populações reduzidas a corpo-espécie, perpassadas e definidas pela mecânica do biológico, uma multidão de sujeitos intercambiáveis e substituíveis.

No momento em que o domínio da ética e da política é reduzido ao campo do biológico, do corpo espécie, nossos sofrimentos individuais e cotidianos, nossos vínculos sociais, medos e desejos passarão a estar mediados por intervenções terapêuticas ou preventivas, sejam elas médicas ou psiquiátricas, interessadas em classificar todos os assuntos próprios da condição humana em termos de 
normalidade ou de patologia, limitando cada vez mais nossa margem de decisão ética e de ação política.

\section{BIOPOLÍTICA E CLASSIFICAÇÃO PSIQUIÁTRICA}

Partindo desse marco de análise podemos afirmar, em primeiro lugar, que a vida não é considerada pela biopolítica em um sentido coloquial, ou vulgar. Pelo contrário, ela leva a carga epistemológica de uma vida objetivada pelos discursos, os modos de classificar, medir, intervir e avaliar próprios das ciências biológicas e médicas, construídos entorno da oposição normal-patológico. Por essa razão a medicina, a higiene e a saúde pública, ocupam um lugar privilegiado nas sociedades modernas, possibilitando a articulação entre os saberes sobre o biológico e as intervenções governamentais sobre indivíduos e populações.

Em segundo lugar pode-se afirmar que a vida à qual se refere a biopolítica não é um complemento da política mas seu oposto, aquilo que anula e nega a política. Como afirma Lazzaratto, a biopolítica "é um fator de despolitização e de neutralização do político" (LAZZARATTO, 2005). Ela não pode entender-se em sentido literal: como uma política da vida, pelo contrário, significa um modo de gestão, de administração, certas estratégias de governo destinadas a uma população reduzida ao domínio das necessidades biológicas e aos processos de nascimento, reprodução e morte. A biopolítica é justamente aquilo que se opõe à política entendida como governo de si, como espaço de constituição ética e política da subjetividade. Aquilo que permite substituir o diálogo argumentativo, essencial para a construção do espaço político, pela urgência, pela imediata e irreflexiva satisfação das necessidades, reduzindo a pluralidade da condição humana a processos biológicos.

Por fim, a vida da biopolítica não se refere a sujeitos capazes de traçar narrativas sobre sua própria história. Ela se refere a sujeitos anônimos e intercambiáveis, cujas histórias carecem de significação, pois do que se trata é de populações, de corpos substituíveis que devem ser maximizados e aperfeiçoados e não de sujeitos morais de suas próprias ações (FOUCAULT, 2008).

Situando a biopolítica nesse espaço de diálogo podemos identificar quatro mecanismos que nos permitem individualizar a especificidade desse modo de exercício de poder estudado por Foucault. Eles são: (1) a centralidade da norma e 
oposição normalidade-patologia; (2) os estudos estadísticos referidos aos fenômenos vitais que caracterizam as populações; (3) a problemática do riscosegurança, isto é, a ideia de que é possível antecipar os riscos para evitar a emergência de futuros danos; (4) estes mecanismos configuram um peculiar modo de exercer o governo sobre as populações que exclui as narrativas dos sujeitos e suas histórias de vida. A gestão das populações enquanto multiplicidade biológica deve deixar nas sombras, como antecipara Aristóteles, nossa capacidade de existência pública e política, os diálogos argumentativos, as narrativas individuais, os vínculos sociais.

Pretendo analisar aqui de que modo operam esses mecanismos no campo da psiquiatria hoje hegemônica, mais especificamente, proponho revisar as críticas recentemente enunciadas pelo psiquiatra americano Allen Frances, chefe do grupo de tarefas do DSM IV. No mês de maio de 2012, num artigo que publica na Revista Psiquiatric Time, afirma:

O DSM-5 persiste em oferecer propostas que inadequadamente causam o rótulo de "transtorno mental" a milhões de pessoas agora consideradas "normais". Estas sugestões não encontram suporte científico e são fortemente combatidas por 51 associações de saúde mental, mas a APA continua a recusar pedidos de revisão externa independente (FRANCES, 2010, p. 6).

Esse artigo retoma os argumentos apresentados em 2010, após a aparição do primeiro rascunho do DSM V, num texto denominado: "Abrindo a caixa de Pandora, as 19 piores sugestões do DSM V" (FRANCES, 2010), onde afirmava que o primeiro rascunho do DSM $V$ antecipava a aparição de uma verdadeira pandemia de transtornos mentais.

Além de realizar uma crítica ao secreto desnecessário que acompanha ao processo de elaboração do Manual, às ambições exageradas e aos métodos pouco rigorosos, ele formula algumas críticas epistemológicas e teóricas que são perfeitamente aplicáveis às anteriores edições do DSM, onde Frances teve uma participação ativa. Neste texto afirma que:

O DSM V poderia criar dezenas de milhões de novos mal identificados pacientes "falso positivos" exacerbando assim, em alto grau, os problemas causados por um já demasiado inclusivo DSM IV. Haveria excessivos tratamentos massivos com medicações desnecessárias, de alto custo e frequentemente bastante prejudiciais (FRANCES, 2012, p.1). 
Trata-se aqui de construir uma estratégia de classificação estatística entorno de um dos três mecanismos apontados aqui como articuladores da biopolítica: a distinção normal-patológico. No entanto, o que Frances identifica como um novo problema não é mais que um fato inerente a toda e qualquer classificação psiquiátrica: a elasticidade dos critérios diagnósticos e a fronteiras difusas e imprecisas existentes entre o normal e o patológico. Essa ambiguidade que Phylippe Pignarre identifica como sendo a maior dificuldade e limitação dos diagnósticos psiquiátricos, é o que possibilita sua elasticidade, sua capacidade de expansão e a indefinida integração de novos diagnósticos e de novos comportamentos de risco às classificações psiquiátricas.

$\mathrm{O}$ fato de que essas propostas levem a classificar inadequadamente com $\mathrm{O}$ rótulo de "transtorno mental" a milhões de pessoas, que antes eram consideradas "normais", não é novo nem acidental, nem resulta de uma escolha metodológica equivocada realizada pelo Grupo de Tarefas do DSM-V. Pelo contrário, trata-se de uma questão teórica e política que é contemporânea à própria ambição classificatória da psiquiatria.

Frances afirma que, se são aceitas as afirmações presentes no rascunho postado pela comissão que elabora o DSM-V, se incrementarão drasticamente as taxas de transtornos mentais na população. Esse processo poderá ocorrer de dois modos: pela criação de novos diagnósticos que transformam em patológicos comportamentos comuns na sociedade, e que a indústria farmacêutica se encarregará de popularizar (como a tristeza, os pequenos déficits de cognição, as explosões de raiva, os comportamentos sexuais, adições a certas condutas cotidianas como comprar, o uso de substâncias tóxicas etc.); e pelo estabelecendo de um umbral de diagnóstico mais baixo para muitas patologias já existentes, um exemplo seria retirar a excepcionalidade concedida aos casos de luto para o diagnóstico de depressão. Trata-se de duas estratégias já presentes nas anteriores edições do Manual e que reaparecem aqui de modo exacerbado.

Em palavras de Frances:

O maior impacto partiria da sugestão de eliminar o critério de "significação clínica" que era requerido no DSM IV para os transtornos onde existem limites difusos com a normalidade (aproximadamente dois terços dos diagnósticos). Eliminando esse requerimento se reduziria o papel do julgamento clínico (...) incrementando-se a já inflacionadas taxas de diagnósticos psiquiátricos (FRANCES, 2012, p. 3). 
Uma pergunta surge de modo inevitável: quem substitui o julgamento clínico do especialista? Ou então: quem determina se certa situação de angústia ou impedimento indicam ou não a existência de uma patologia psiquiátrica uma vez eliminado o critério de "significação clinica"?

A resposta a essa pergunta exige fazer referência ao segundo mecanismo articulador da biopolítica antes mencionado: o uso das estatísticas, das médias e desvios populacionais. Pois, o que substitui a avaliação da significação clínica, serão novas estratégias diagnósticas, com maior pretensão de objetividade, que incluem a aplicação de testes, de check list, de valorações dimensionais para rasgos de personalidade, pontuações de severidade, enfim, todo um arsenal quantitativo que já estava presente nas edições anteriores do DSM e que no DSM V se intensifica.

O uso de instrumentos quantitativos no campo da psiquiatria não é novo, ele já estava presente desde a construção da primeira classificação unificada de patologias mentais realizada em 1898 e foi esse um instrumento essencial que possibilitou a elaboração das anteriores edições do Manual de Diagnóstico e Estatística de Perturbações Mentais (DSM).

O deslocamento do olhar clínico em favor de parâmetros pretensamente mais objetivos, como o uso de instrumentos estatísticos de avaliação e diagnóstico, está diretamente associada à dificuldade para estabelecer fronteiras mais ou menos precisas entre normalidade e patologia psíquica num campo que, como a psiquiatria, se legitima com os parâmetros da medicina clinica indissoluvelmente vinculado a essa polaridade. As estatísticas substituem aqui os parâmetros de validação clássicos utilizados pela medicina clínica, como a identificação de lesões orgânicas ou de marcadores biológicos.

Por fim, o contínuo normal-patológico e sua operacionalização estatística permitirão a identificação do terceiro mecanismo, essencial para a construção de uma biopolítica dos sofrimentos psíquicos. A identificação precoce de riscos e a necessidade de intervir e medicar os desvios, isto é, a instalação da estratégia biopolítica identificada por Foucault como o dispositivo "risco-segurança" (FOUCAULT, 1997, 2004, 2005).

É possível afirmar que uma das estratégias indispensáveis para garantir a indefinida ampliação de diagnósticos e categorias psiquiátricas é a obseção por identificar pequenas anomalias, angústias cotidianas, pequenos desvios de conduta 
como indicadores de uma patologia psiquiátrica grave por vir. O risco, na medida em que aparece como um modo de antecipar um perigo possível (real ou imaginado) sobre a vida e a saúde, constitui a estratégia biopolítica por excelência que permite garantir a legitimidade e aceitabilidade desse modo de exercer o governo das populações.

A ambição por identificar comportamentos de risco cada vez mais sutis, com a finalidade de construir uma psiquiatria preventiva, é central para compreender o modo como os pequenos desvios de conduta e as tristezas cotidianas ingressam no campo das intervenções psiquiátricas iniciando um verdadeiro processo de medicalização do não patológico.

Será entorno à problemática do risco e da segurança (no duplo sentido de segurança para o doente e para a sociedade) que se estrutura o Tratado de Degeneração Física, Mental e Moral de Morel em 1857; os estudos de Magnan sobre alcoolismo de 1893; o discurso dos higienistas e diversos textos de Kraepelin. Em cada um desses autores o problema do risco e o projeto de detecção precoce de problemas psiquiátricos a partir da observação de comportamentos normais se vincula, de modo diferente, com suas propostas de classificar patologias mentais (CAPONI, 2012). Porém, será a partir de 1980, com a publicação do DSM III que essa biopolítica se generaliza no campo do saber psiquiátrico.

A cada nova edição do DSM, se repete a mesma certeza de que a identificação precoce de comportamentos considerados de risco permitirá, no futuro, evitar a cronificação de certas patologias psiquiátricas. Porém, é justamente esse processo de identificação de comportamentos de risco, o que permite criar novas patologias psiquiátricas leves e de identificação ambígua que poderão passar a ser adicionadas às classificações de diagnósticos psiquiátricos já existentes.

É essa lógica a que se evidencia no texto de Frances, aqui analisado, quando afirma que:

Os psiquiatras esperam identificar pacientes mais cedo e criar tratamentos efetivos para reduzir a cronicidade das patologias. Desafortunadamente, os membros do Grupo de Tarefas usualmente têm o ponto cego de esquecer que qualquer esforço por reduzir as taxas de falsos negativos deve inevitavelmente elevar as taxas de falsos positivos (frequentemente de modo dramático e com fatais consequências). Se alguma vez será possível lograr a esperada vantagem da detecção precoce de casos, deveremos ter provas diagnósticas específicas e tratamentos seguros. Em contraste as propostas do DSM V leva à particularmente perigosa combinação de 
diagnósticos não específicos e inadequados, e a tratamentos não provados e danosos (FRANCES, 2010, p. 6).

Um dos muitos exemplos apresentados por Frances é a síndrome de risco de psicose. Nesse caso, segundo afirma, conta-se com a alarmante taxa de falsos positivos de 70 a $75 \%$. Isso implica que, desse modo, centenas de milhares de adolescentes e jovens podem vir a receber, sem necessidade, a prescrição de antipsicóticos atípicos que causam efeitos colaterais sérios como aumento de peso, impotência sexual e redução da expectativa de vida, danos severos no sistema digestivo, dentre outros.

A problemática do risco e a ambição pela deteç̧ão precoce de indivíduos com a probabilidade de vir a padecer uma patologia psiquiátrica que pode ser prevenida antes que se cronifique, é um dos grandes tópicos que acompanharam à psiquiatria moderna ao longo da sua história. Esse princípio tem levado a um processo maciço de medicalização da infância que se inicia com o nascimento da psiquiatria moderna e permanece até hoje.

\section{A MODO DE CONCLUSÃO}

É provável que um olhar atento e cuidadoso sobre os diversos modos pelos quais as classificações psiquiátricas lidaram com a temática do risco, da prevenção e dos dispositivos de segurança, com a distinção normal/patológico, e com os processos de quantificação dos sofrimentos, nos permita retomar uma pergunta que Frances formula em sua crítica. Quando interrogado sobre a possibilidade de que a expansão do número de diagnósticos não se deva a motivos clínicos, mas à influência, cada vez maior, da indústria farmacêutica, dos planos e seguros de saúde, ou, enfim, de questões econômicas de custo-benefício, ele negará absolutamente essa possibilidade.

Nesse contexto, e em defesa de seus colegas do Grupo de Tarefas, ele se pergunta: "Como podem pessoas tão inteligentes e escrupulosas fazer tantas sugestões ruins?" (Frances, 2010, p. 5). Dando a essa pergunta uma ambígua e estranha resposta, ele dirá:

Tem sido minha experiência consistente (obtida trabalhando nos três prévios DSMs) que cada grupo de Trabalho tem sempre uma forte (frequentemente irresistível) ânsia de expandir os limites das desordens de 
sua seção. Esse previsível imperialismo de diagnóstico dos Grupos de Tarefa deve ser sempre reconhecido e resistido. Os expertos tem muita expectativa em reduzir os falsos negativos para seus transtornos favoritos e em anular a necessidade de recorrer à etiqueta "não especificado de outro modo" (FRANCES, 2012, p. 5).

Dificilmente poderíamos construir um exemplo mais claro do modo como opera esta biopolítica dos comportamentos cotidianos e dos sofrimentos psíquicos leves. Ainda que possa resultar impensável imaginar um grupo de cardiologistas que defenda sua "ânsia irresistível de multiplicar os transtornos cardíacos" ou de "expandir os limites de seus diagnósticos favoritos", essa parece ser a estratégia que sustenta a expansão dos diagnósticos referidos a sofrimentos psíquicos leves. Criase assim uma aliança indissociável entre um discurso de verdade (uma classificação diagnóstica cujos limites se expandem cada vez mais) e uma estratégia de poder (que opera com a lógica do dispositivo de segurança).

As consequências que a aceitação dessa aliança pode ter no modo como cada um de nós lida com seus sofrimentos psíquicos, mais ou menos leves, pode ser determinante na escolha do modo como construímos nossa subjetividade, do modo como respondemos a nossos desafios e problemas. Chegamos assim ao último dos elementos antes apontados como constitutivos da biopolítica das populações. Para compreender essa dimensão da biopolítica como governo dos outros que exclui e silencia o governo de si, será necessário sair dos textos que Foucault dedica à biopolítica da população para lembrar brevemente o curso do College de France ministrado em 1982, denominado O Governo De Si e Dos Outros (FOUCAULT, 2008).

Pelo que foi dito até aqui, a biopolítica dos sofrimentos psíquicos, aqui analisada, aparece com um modo de exercer o governo sobre os outros que se vale de critérios pretensamente científicos e validados de classificação e que privilegia um modo de intervenção: a terapêutica farmacológica. Esse dispositivo exclui as narrativas dos sujeitos e suas histórias de vida ou as subordina a explicações biológicas referidas a alterações ou déficit nos neurotransmissores. Como já foi dito, é próprio da biopolítica deixar nas sombras nossa capacidade de existência pública e política, os diálogos argumentativos, as narrativas individuais, os vínculos sociais.

Quiçá possamos entender a aceitação dessa aliança se pensamos que o processo de ampliação de patologias psiquiátricas, na medida em que supõe a exclusão das narrativas e das histórias de vida dos pacientes, substitui a dimensão 
ética de nossa existência, a construção subjetiva do eu, pela obediência ao governo que autoridades externas (médicas ou psiquiátricas) exercem sobre nossas vidas.

No momento em que os sofrimentos deixam de fazer parte de nossa história para ser pensados em termos de déficit de serotonina ou de noradrenalina, ingressamos no domínio de especialistas que definem nossos padecimentos com diagnósticos específicos e limitam nossas possíveis escolhas a uma terapêutica privilegiada: a resposta farmacológica. Esse processo nos inibe de exercer plenamente o governo sobre nós mesmos, mantendo-nos no registro da minoridade, da cômoda obediência a mandados externos. Do dito até aqui podemos concluir que, como afirma Pignarre, resulta necessário

abandonar o método de diagnóstico existente e compreender o sofrimento psíquico como uma experiência que se inscreve na duração de uma vida, que se transforma de acordo ao modo como a enunciamos, o modo como somos ouvidos e às intervenções e terapêuticas propostas (PIGNARRE, 2006, p. 76).

De modo que em lugar de perguntar: "Como podem pessoas tão inteligentes e escrupulosas fazer tantas sugestões ruins?". Provavelmente seria mais interessante reformular a pergunta nos seguintes termos: "Quais são as razões que nos levam, a cada um de nós, a aceitar uma biopolítica dos sofrimentos leves que, inadequadamente, pode chegar a aplicar o rótulo de 'transtorno mental' a milhões de pessoas que hoje são consideradas 'normais'?". A resposta a esta pergunta já não poderá ser procurada nas médias estatísticas, nos parâmetros de normalidade e patologia, nem nas classificações de diagnóstico, mas no campo do governo de si, na capacidade de criar redes terapêuticas capazes de nos auxiliar no complexo processo de construção reflexiva de nossa subjetividade (FOUCAULT, 2008). 


\section{REFERÊNCIAS}

AGAMBEN, G. Homo Sacer. Belo Horizonte: Ed. UFMG, 2002

ARENDT, H. La Condición Humana. México: Siglo XXI, 1993.

CAPONI, S. Da Compaixão à solidariedade: uma genealogia da assistência médica. Ed. Fiocruz, Rio de Janeiro, 2000.

Ed. Fiocruz, Rio de Janeiro, 2012.

Loucos e Degenerados: uma genealogia da psiquiatria ampliada.

CANGUILHEM, G. La Santé. Concept Vulgaire \& Question Philosophique. Paris: Ed. Sables. 1990b.

CANGUILHEM, G. O normal e o patológico. Rio de Janeiro: Forense Universitaria, 1990a.

CASTIEL, L. A Saúde Persecutória e os limites da responsabilidade. Rio de Janeiro. Ed. Fiocruz, 2007.

FASSIN, D. Le gouvernement des corps. Paris: Editions de l'école des Hautes Etudes en Sciences Sociales, 2006.

FOUCAULT, M. Historia de la Sexualidad I: la voluntad de saber. México: Siglo $\mathrm{XXI}, 1978$.

Vigilar y Castigar. México: Siglo XXI, 1979.

Las Palabras y las Cosas. México: Siglo XXI, 1983.

. El Nacimiento de la Clínica. México: Siglo XXI, 1987.

. II Faut Défendre la Societé. Paris: Gallimard, 1997.

. Les Anormaux. Paris: Gallimard, 1999. 
Securité, Territoire, population. Paris: Gallimard, 2004.

. Naissance de la Biopolitique. Paris: Gallimard, 2005.

Le gouvernement de soi et des autres. Paris: Gallimard, 2008.

FRANCES, A. Opening Pandoras Box: The 19 Worst Suggestions For DSM5. Rev.Psychiatric Times. Vol.1 No. February 11, 2010.

FRANCES, A. DSM 5 Continues to Ignore Criticism From Petitioners. Posted: 06/20/2012 5:56 pm. Disponível em: http://www.huffingtonpost.com/allenfrances/dsm-5-petition b 1610569.html?view=print\&comm ref=false.

GARCIA MALDONADO, G. et ali. EI DSM-V. Luces y sombras de un manual no publicado.Retos y expectativas para el futuro. Revista Salud Mental. n. 34. pp. 367378. Madrid, 2011.

LAZZARATTO, M. Biopolitique/Bioéconomie. article publié initialement dans la revue Multitudes, $n^{\circ} 22$, automne, 2005.

MARTINEZ HERNÁEZ, A. Antropología Médica: teorías sobre la cultura, el poder y la enfermedad. Barcelona: Anthropos Editorial, 2008.

ORTEGA, F. Biopolíticas da Saúde: reflexões a partir de Michel Foucault, Agnes Heller e Hannah Arendt. In: Ver. Interface, Comunicação, Saúde e Educação. V. 8, n.14, p.9-20. 2004.

PIGNARRE, P. Les malheurs des psys: psychotropes et médicalisation du social. Paris: La Découverte. 2006. 178 p.

Dossiê:

Recebido em: Setembro/2012

Aceito em: Novembro/2012 